\title{
Numerical Simulation on the Basic Rules of Multihole Linear Codirectional Hydraulic Fracturing
}

\author{
Weiyong Lu $\mathbb{D}^{1}{ }^{1}$ Yonglong Wang, ${ }^{2}$ and Xin Zhang $^{3}$ \\ ${ }^{1}$ Department of Mining Engineering, Luliang University, Lvliang, Shanxi 003300, China \\ ${ }^{2}$ School of Energy Science and Engineering, Henan Polytechnical University, Jiaozuo, Henan 454000, China \\ ${ }^{3}$ School of Minerals and Energy Resources Engineering, Faculty of Engineering, University of New South Wales, \\ Sydney NSW 2052, Australia \\ Correspondence should be addressed to Weiyong Lu; 489698551@qq.com
}

Received 16 August 2019; Revised 6 October 2019; Accepted 25 October 2019; Published 3 March 2020

Academic Editor: Shengnan Nancy Chen

Copyright (c) 2020 Weiyong Lu et al. This is an open access article distributed under the Creative Commons Attribution License, which permits unrestricted use, distribution, and reproduction in any medium, provided the original work is properly cited.

\begin{abstract}
Directional rupture is one of the most important and common problems in rock breaking engineering. The purpose of directional rock breaking can be effectively realized by using multihole linear codirectional hydraulic fracturing. In this paper, realistic failure process analysis (RFPA) software is used to verify the experimental results of multihole linear codirectional hydraulic fracturing and investigate its basic law. The following results are demonstrated: (1) RFPA software can be very helpful to study the basic law of multihole linear codirectional hydraulic fracturing; (2) the process of multihole linear codirectional hydraulic fracturing can be divided into four stages: water injection boost, fracture initiation, stable fracture propagation, and fracture connection; and (3) multihole linear codirectional hydraulic fractures propagate along the direction of borehole distribution. Multihole codirectional hydraulic fracturing is influenced by the angle between the direction of the hole distribution and maximum principal stress, the difference of the principal stress, and the spacing of the boreholes. The smaller the angle, the difference value of the principal stress, and the hole spacing, the better the multihole codirectional hydraulic fracturing effect.
\end{abstract}

\section{Introduction}

At present, directional hydraulic fracturing technology has made a significant difference in the control of coal seam hard top roof [1-4], the weakening and falling of hard top coal [5, 6], the control of rock burst [7-9], gob retaining roadway, and the increased permeability of methane-bearing coal seam and shale oil and gas layer [10-12].

In the process of hydraulic fracturing, the initiation and propagation of hydraulic fractures are the core of the design of hydraulic fracturing, and the initiation pressure and direction of fractures determine the range and effect of hydraulic fracturing. Among them, the stress field, the mechanical characteristics of coal and rock mass, and the layout of boreholes are all basic factors in the design of hydraulic fracturing parameters. In recent years, a large number of studies on the mechanism of directional hydraulic fracturing and the field application of a coal mine have been performed by scholars at home and abroad. Directional hydraulic fracturing can be achieved by three methods as described below: (1) Directional hydraulic fracturing guided by a guiding groove [13-16]: the wedge-shaped grooves are cut along the axial or radial direction of the borehole. The stress concentration makes the fracture propagate along the direction of the wedge-shaped grooves. Due to the limitation of stress concentration around the fracture tip of the groove depth, the initiation and propagation of directional cracks are strongly affected. (2) Directional hydraulic fracturing by water jet preslotting [17-22]: a preslot is cut by water jet slotting along the desired direction of around the borehole, and then, hydraulic fracturing is performed. As a result, hydraulic fracture propagates along the direction of the preslot at first. However, after the formation of hydraulic fractures, the fractures will turn in space due to the comprehensive influence of in situ stress, engineering mining, and other factors, and the range of directional fracturing is very 
limited. (3) Directional hydraulic fracturing controlled by multiholes [23-25]: the directional propagation of hydraulic fracturing is realized by adjusting the fracturing boreholes or their surrounding guiding boreholes. Among them, hydraulic fracturing in which multiple holes are arranged along the expected direction of the fracture propagation to achieve the directional propagation is termed as directional hydraulic fracturing controlled by multiholes [23]. The directional hydraulic fracturing controlled by multiholes can realize the directional propagation of hydraulic fractures and improve the range of directional fracturing. Many studies have been performed on the fracture propagation rules of the first two directional hydraulic fracturing. However, research on fracture initiation and propagation rules of the directional hydraulic fracturing controlled by multiholes is still in the stage of exploration and improvement and needs to be further studied.

At present, research on hydraulic fracturing controlled by multiholes is mainly performed by arranging the fracturing holes in a line or arranging the fracture borehole around the fracturing boreholes. According to the layout of the guide holes, the hydraulic fracturing controlled by multiholes can be divided into two cases: (1) Through the layout of multiguide holes around the fracturing borehole, the auxiliary free surface is formed in more directions due to the pressure relief of the guiding holes. More weak planes of fracture propagation and point effect are created, resulting in mutual penetration of hydraulic fractures along more directions. Although a complicated network of hydraulic fracturing can be formed, the direction of hydraulic fractures cannot be controlled [26-28]. (2) One or more guide holes are distributed in a line of two fracturing boreholes. Under pressure relief of the guide holes, hydraulic fractures will directionally propagate along the line of the fracturing boreholes. The more guide holes, the better the effect of directional propagation and the larger the directional propagation range of hydraulic fracturing $[23,24,29,30]$. Recently, multihole linear directional hydraulic fracturing is proposed by Zhao et al. This technology first arranges multiple fracturing holes in a straight line. Then, water is poured into all the fracturing holes with equal displacement, which can achieve directional propagation of hydraulic fracturing in a relatively short time [25]. However, few studies have been conducted on the effects of in situ stress, fracturing hole arrangement, and space between holes on the initiation and propagation of hydraulic fracture.

In this paper, using the solid-liquid coupling software of RFPA2D-Flow, the initiation and propagation rules of multihole linear codirectional hydraulic fracture are studied. Meanwhile, the influence of the layout, number of fracturing holes, and in situ stress on the effect of multihole linear codirectional hydraulic fracturing is also studied, which is helpful to guide the engineering practice.

\section{Numerical Simulation Principle of RFPA Software}

A detailed description of the coupled FSD (flow-stress-damage) model of RFPA has been previously presented [31,32]. Because RFPA software will be utilized in the following sec- tions, a brief summary of RFPA will be introduced first in the following section.

2.1. Basic Assumptions. RFPA2D software has the following basic assumptions:

(1) Fluid that flows in rock mass follows the Biot seepage theory

(2) Rock medium is elastic-brittle material with residual strength, and its mechanical behaviour during loading and unloading processes conforms to the elastic damage theory

(3) The maximum tensile strength criterion and MohrCoulomb criterion are used as damage thresholds to judge the damage of the cell

(4) In the elastic state, the relationship between stress and the permeability coefficient of the material is described by a negative exponential equation. After the material is damaged, the permeability coefficient increases obviously

(5) The mechanical parameters of the microstructure of the material are assigned according to the Weibull distribution to provide the nonuniformity of the material

2.2. Seepage-Stress Coupled Governing Equation. As a numerical code, RFPA can simulate the failure process of quasibrittle materials, such as rock. The finite element method (FEM) is utilized to analyse the basic stress and fluid flow. The fournode isoparametric element is applied as the basic element mesh.

The failure strength of a rock can vary significantly on account of grain-scale heterogeneity. The mechanical parameters of the finite elements in RFPA are assumed to conform to a Weibull distribution [33]:

$$
f(u)=\frac{m}{u_{0}}\left(\frac{u}{u_{0}}\right)^{m-1} \exp \left(-\frac{u}{u_{0}}\right)^{m}
$$

where $u$ represents the variables, such as Young's modulus, Poisson's ratio, or strength properties; $u_{0}$ represents the corresponding mean value; and $m$ defines the shape of $f(u)$ representing the degree of heterogeneity, which can be called the heterogeneity index. Detailed studies of the heterogeneity index $m$ have been introduced by Tang et al.

The seepage-stress coupled equation adopted by RFPA2D-Flow software is described as follows:

$$
\text { Equilibrium equation : } \frac{\partial \sigma_{i j}}{\partial X_{i j}}+\rho X_{j}=0, \quad i, j=1,2,3 \text {, }
$$

$$
\text { Geometric equation : } \varepsilon_{i j}=\frac{1}{2}\left(u_{i, j}+u_{j, i}\right), \quad i, j=1,2,3 \text {, }
$$


Constitutive equation : $\sigma_{i j}^{\prime}=\sigma_{i j}-\alpha p \delta_{i j}=\lambda \delta_{i j}+2 G \varepsilon_{i j}$,

$$
i, j=1,2,3 \text {, }
$$

Seepage equation : $k \nabla^{2} p=\frac{1}{Q} \frac{d p}{d t}-\alpha \frac{\partial \varepsilon_{\mathrm{v}}}{\partial t}$,

Permeability equation : $k(\sigma, p)=\xi k_{0} \exp \left[-\beta\left(\frac{\sigma_{i i}}{3-\alpha p}\right)\right]$,

$$
i, j=1,2,3 \text {. }
$$

Equations (2)-(5) are built on Biot's theory of consolidation [34], and Equation (6) represents the effect of stress on permeability [35]. Here, $\sigma_{i j}$ is the stress tensor in the solid, $X_{i j}$ is the vector space, $\rho$ is the density of the fluid, $\varepsilon_{i j}$ is the strain, $u_{i, j}$ is the displacement vector, $\alpha$ is the coefficient of pore pressure, $p$ is pore pressure, $\delta_{i j}$ is the Kronecker delta function, $\lambda$ is the Lame coefficient, $G$ is the modulus of shear deformation, $k$ is the permeability coefficient considering stress and damage evolution in the individual rock element, $Q$ is Biot's constant, $t$ is time, $\varepsilon_{\mathrm{v}}$ is the strain of volume, $k_{0}$ is the initial permeability coefficient of an intact rock element, $\beta$ is the coupling parameter signifying the impact of stress on the coefficient of permeability, and $\xi(\xi \geq 1.0)$ is a muta- tion coefficient of the permeability coefficient that takes the increase in the permeability coefficient into account once the element reaches the damage state. It is assumed that $\xi=5$ for the damaged element (indicated by $0<D<1$ ) and $\xi=100$ for the fully damaged element (indicated by $D=1 ; D$ represents the damage variable that will be illustrated in the following) [36]. Here, we need to indicate that the permeability, $k$, for an individual element is assumed to be constant at the current time; however, the permeability coefficients of all elements in the entire domain may be different from each other. Additionally, it is important to emphasize that Newtonian fluid is assumed for the rheology of the fluid, and the non-Newtonian behaviour of fluid is not considered during this study.

2.3. Seepage-Damage Coupled Equation. When the stress or strain state of the element reaches a given damage threshold, the element begins to damage, and the elastic modulus of the damage element can be expressed as follows [37, 38]:

$$
E=(1-D) E_{0}
$$

(1) When the shear stress of the element reaches the Mohr-Coulomb damage threshold:

$$
\begin{aligned}
& \text { Damage variable }: D= \begin{cases}0, & \varepsilon<\varepsilon_{c 0}, \\
1-\frac{f_{c r}}{G_{0} \varepsilon}, & \varepsilon_{c 0} \leq \varepsilon,\end{cases} \\
& \text { Permeability coefficient of the element : } K= \begin{cases}K_{0} \exp ^{-\beta\left(\sigma_{1}-\alpha p\right)}, & D=0, \\
\xi \exp ^{-\beta\left(\sigma_{1}-\alpha p\right)}, & D \leq 0,\end{cases}
\end{aligned}
$$

(2) When the force on the element reaches tensile strength $f_{t}$ :

Damage threshold : $\sigma_{3} \leq-f_{t}$,

Damage variable $D: D= \begin{cases}0, & \varepsilon_{c 0} \leq \varepsilon, \\ 1-\frac{f_{c r}}{G_{0} \varepsilon}, & \varepsilon_{t u} \leq \varepsilon<\varepsilon_{0}, \\ 1, & \varepsilon \leq \varepsilon_{t u},\end{cases}$

Permeability coefficient of the element : $K= \begin{cases}K_{0} \exp ^{-\beta\left(\sigma_{3}-\alpha p\right)}, & D=0, \\ \xi K_{0} \exp ^{-\beta\left(\sigma_{3}-\alpha p\right)}, & 0<D<1, \\ \xi K_{0} \exp ^{-\beta\left(\sigma_{3}-p\right)}, & D=1 .\end{cases}$ 


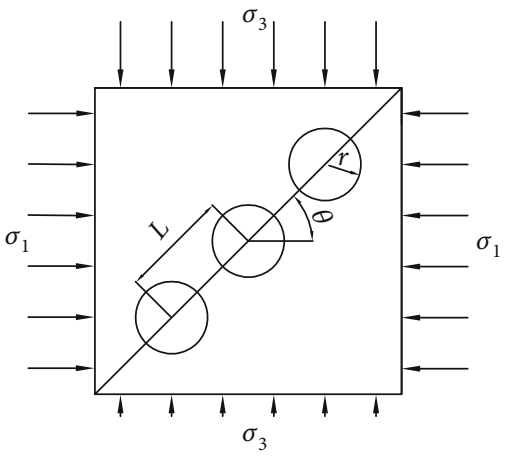

FIGURE 1: Geometric model.

Here, $D$ is damage variable; $E$ and $E_{0}$ are the elastic modulus of damaged element and undamaged element, respectively, which are assumed to be scalar quantities; $\varphi$ is friction angle; $f_{c}$ is uniaxial compressive strength; and $f_{c r}$ is residual strength.

2.4. Solving Method. Under the action of complex stress and the damage evolution process of rock mass, the seepagestress coupled equation is built by this model. The seepage and linear elastic stress are calculated by the finite element method, and the equations are solved by the method of coupled iterative cycles.

\section{Verification of the Mathematical Model}

3.1. Geometric Model. The two-dimensional plane stress model with a size of $500 \mathrm{~mm} \times 500 \mathrm{~mm}$ is adopted in this numerical simulation (Figure 1). Confining pressure is applied at each boundary of the model. The bottom boundary of the model was fixed, and the seepage of each boundary is impenetrable. The hole diameter is $10 \mathrm{~mm}$, and the model is divided into $250 \times 250$ cells. The maximum principle stress $\sigma_{1}$ is $6 \mathrm{MPa}$ in the horizontal direction, and the minimum principle stress $\sigma_{3}$ is $2 \mathrm{MPa}$ in the vertical direction. Three boreholes are arranged in a linear direction, and water is injected into the three boreholes simultaneously. The initial water pressure applied in the boreholes is $0 \mathrm{MPa}$, and it increases by $0.2 \mathrm{MPa}$ for each step.

3.2. Parameter Determination. To ensure that the numerical calculation can more closely simulate the real physical experiment, the real physical parameters of the experimental sample are adopted in the numerical simulation as much as possible. The relevant parameters used in this numerical simulation are shown in Table 1 . The parameters, such as compressive and tension strength, can be obtained by a mechanical test, and their proportion and internal friction angle can be calculated. And then, the stress-strain curve can be obtained. Moreover, the residual strength coefficient, the maximum tension and compressive strain coefficient, the elastic modulus, and the internal friction angle are very easy to obtain. The permeability can be obtained by the laboratory experiment. Before water is poured into the borehole, there is no water pressure. Therefore, initial water pressure is
0 . The same value of tension strength $1.64 \mathrm{MPa}$ and uniaxial compressive strength $6.27 \mathrm{MPa}$ as the value of mechanical parameters of the cement mortar is utilized in the numerical simulation.

3.3. Comparison of Numerical Simulation and Experimental Results. Under the condition of water injection with the same displacement in three holes, the coupled effect between the holes is relatively enhanced, and hydraulic fracture propagates and links up along the line connected by the borehole's center. The morphology of hydraulic fracture propagation obtained by numerical simulation (Figure 2(a)) is generally consistent with that obtained by physical experiments (Figure 2(b)). It is generally feasible to utilize RFPA2DFlow software to study the fracture initiation and propagation rules of multihole linear codirectional hydraulic fracturing.

\section{Process, Basic Rule, and Influencing Factors of Fracture Initiation and Propagation of Multihole Linear Synergistic Directional Hydraulic Fracture}

4.1. Initiation and Propagation Process of Hydraulic Fracturing. The process of multihole linear codirectional hydraulic fracturing can be divided into the water injection boost stage, fracture initiation stage (Figure 3(a)), fracture stable propagation stage (Figure 3(b)), and fracture connection stage (Figure 3(c)). The following features are noted for the four stages: (1) In the water injection boost stage, no fracture occurs. (2) The tested block is characterized with large strength, large brittleness, and small plasticity. Therefore, as the water pressure increases, considerable energy is accumulated within the tested block in the initial stage of the hydraulic fracture. When the water pressure reaches the breaking condition, a hydraulic fracture will occur immediately, and its external performance is the initial rupture. When the tested block comes to the first rupture, the speed of the hydraulic fracture propagates very fast, and considerable energy is released. As a result, the initial fractures are large. (3) At any time of the stable propagation stage of the hydraulic fracture, the injection of fracturing fluid will increase the pressure, fracture width, and rock stress in the fracture before the fracture continues to propagate. When the stress or deformation of the fracture tip reaches the strength of the material, the fracture will propagate forward for a certain distance. The propagation behaviour of fractures depends on the propagation zone, which depends on the dimensionless fracture toughness. When the toughness of the dimensionless fracture is small, the propagation zone is dominated by viscosity, and the energy dissipation generated by the opening of the fracture surface is considerably less than that of the fluid. When the dimensionless fracture toughness is large, the propagation zone is dominated by toughness, and the energy dissipation generated by the opening of the fracture surface is considerably increased compared with that in the fluid. In the early stage of fracture propagation, the dominant zone of toughness often plays an important role. With the continuous expansion of the fracture surface, the energy dissipation occupied by fluid in 
TABLe 1: Parameters used in this numerical simulation.

\begin{tabular}{|c|c|c|c|}
\hline Name of parameter & Value and unit & Name of parameter & Value and unit \\
\hline Tension strength $\sigma_{\mathrm{t}}$ & $1.64 \mathrm{MPa}$ & Internal friction angle & $31.2^{\circ}$ \\
\hline Elastic modulus $E$ & $0.72 \mathrm{MPa}$ & Residual strength & $0.1 \%$ \\
\hline $\begin{array}{l}\text { Proportion of tensile strength and } \\
\text { compressive strength }\end{array}$ & 3.8 & Pore water coefficient & 0.1 \\
\hline Permeability coefficient $k$ & $0.0006 \mathrm{~m} / \mathrm{d}$ & Maximum compression strain coefficient & 200 \\
\hline Maximum tension strain coefficient & 1.5 & $\begin{array}{l}\text { Angle } \theta \text { between the line of the borehole's core and } \\
\text { direction of maximum principle stress }\end{array}$ & $15^{\circ}$ \\
\hline Initial water pressure $p_{\mathrm{w} 0}$ & $0 \mathrm{MPa}$ & Increased water pressure $\Delta p_{\mathrm{w}}$ for each step & $0.2 \mathrm{MPa}$ \\
\hline Horizontal principal stress $\sigma_{1}$ & $6 \mathrm{MPa}$ & Vertical principal stress $\sigma_{3}$ & $4 \mathrm{MPa}$ \\
\hline
\end{tabular}

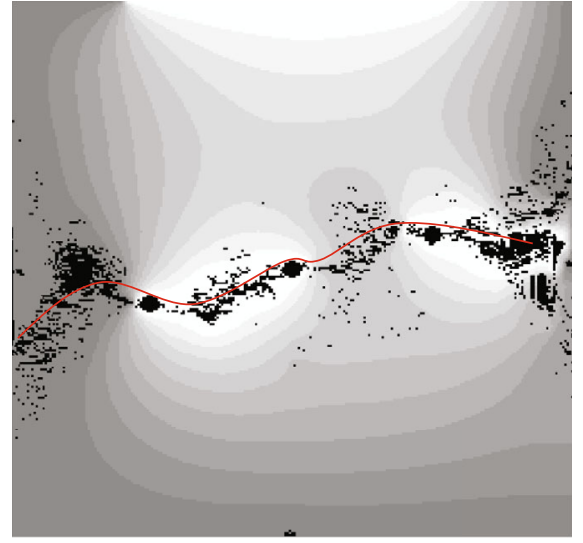

(a) Numerical simulation result

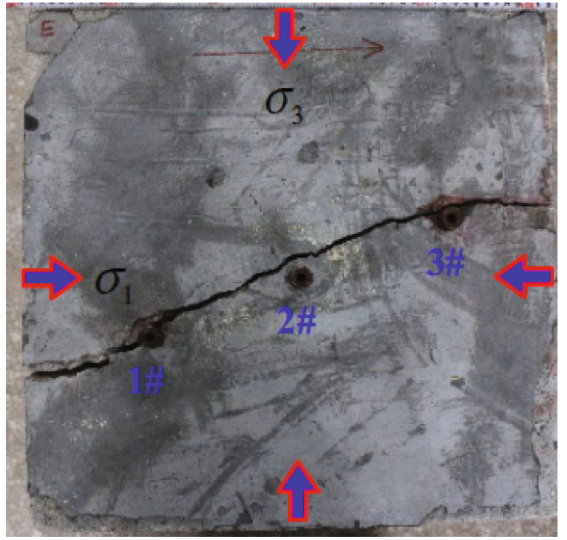

(b) Experimental result [25]

Figure 2: Comparison of numerical simulation and experimental results.

the fracture increases, and the dominant zone of viscosity often plays a major role. With continuous water injection, the accumulated energy of the tested block is released stably, and the hydraulic fracture is in the stage of stable propagation, which is manifested externally as the continuous and stable rupture of the tested block. (4) In the fracture penetration stage, the length of the fracture increases as water pressure increases, and the propagation speed gradually slows down. This finding is explained by the fact that as the process of water injection continues, the brittleness of the tested block decreases; however, its plasticity increases. The energy is released to a certain extent due to the generation of new fractures. When the energy is difficult to accumulate in considerable quantities, the breaking termination condition is reached, and the external performance is noted given that the propagation speed of the fracture gradually slows down or even reaches 0 .

4.2. Basic Rules of Initiation and Propagation of Hydraulic Fracturing. The results of the numerical simulation of multihole linear codirectional hydraulic fracturing are shown in Figure 3. The hydraulic fracture basically extends along the line direction of the hole center rather than just along the direction of the maximum principal stress. During the multihole linear codirectional hydraulic fracturing, the effect of the macroscopic stress field on the propagation guidance of the hydraulic fracture is weakened due to the increase in the coupled effect between the holes. As soon as the hydraulic fracture starts to generate, it begins to turn. As a result, hydraulic fractures gradually propagate along the direction of the hole's center and connect to each other. Outside the range of space between holes, the effect of the macroscopic in situ stress field on hydraulic fracture propagation becomes weaker as well. The propagation of the hydraulic fracture is easily affected by generated fractures and continues to expand along the direction of generated fractures to achieve directional propagation and the penetration effect of multihole linear codirectional hydraulic fracturing. This process occurs because the rock is permeable. A filtration effect of water flowing inside the rock is observed. As the water pressure increases in the borehole, the borehole wall undergoes compression deformation. Tensile stress, which is perpendicular to the line of the borehole center, is generated due to the mutual compression between boreholes. With multiple boreholes arranged on the same straight line, the tensile stress of the boreholes will be superimposed. As a result, the tensile stress at the intersection of the borehole center line and the borehole wall will come to the maximum value. When the value is greater than the tensile strength of the rock, the rock will start to fracture, and water flows into the fracture and 


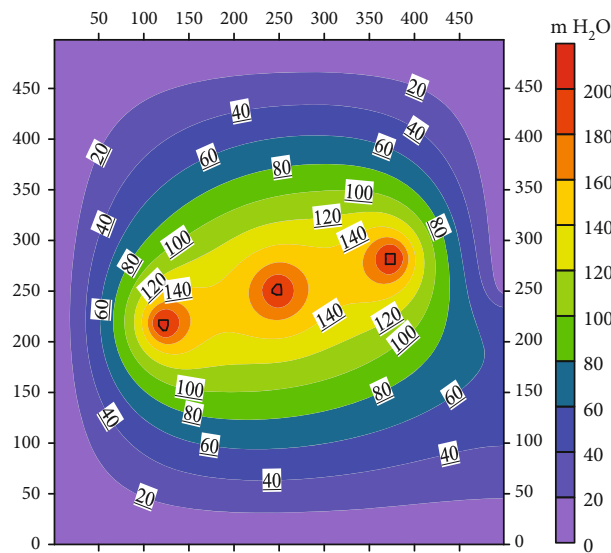

$\begin{array}{lllllllll}50 & 100 & 150 & 200 & 250 & 300 & 350 & 400 & 450\end{array}$

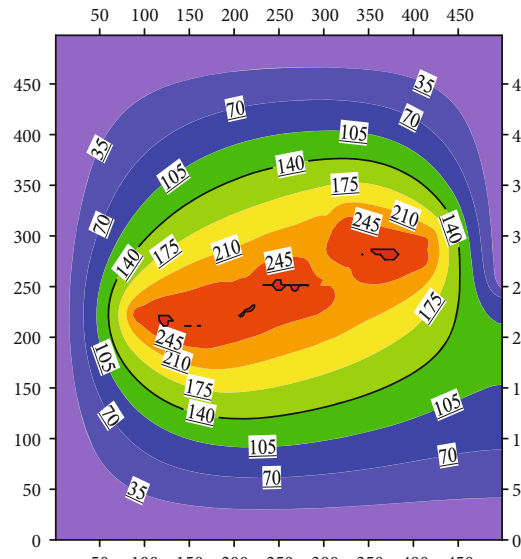

$\begin{array}{lllllllll}50 & 100 & 150 & 200 & 250 & 300 & 350 & 400 & 450\end{array}$

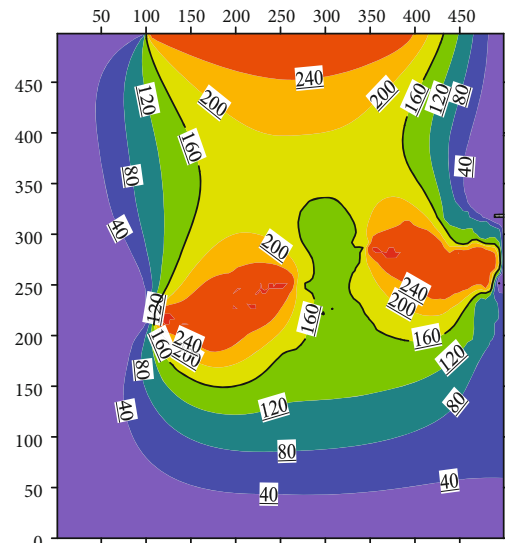

$\begin{array}{lllllllll}50 & 100 & 150 & 200 & 250 & 300 & 350 & 400 & 450\end{array}$

(a) Distribution of water pressure

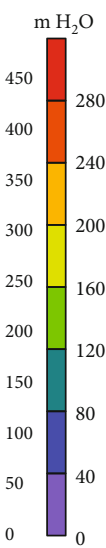

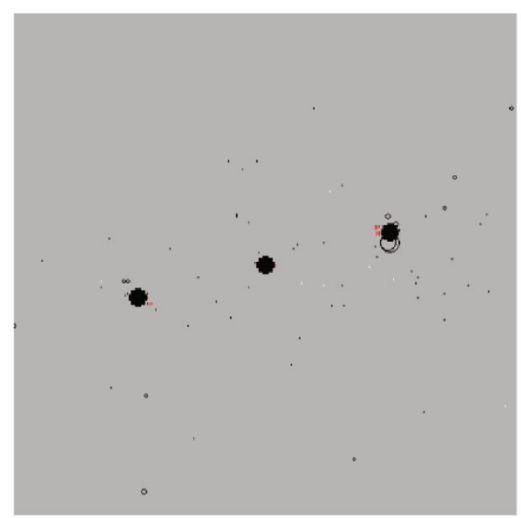

(A) Initiation stage of hydraulic fracture

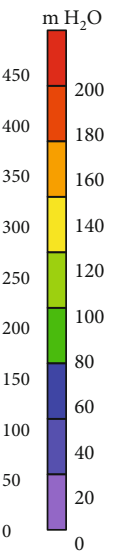

(B) Stable rupture of hydraulic fracture

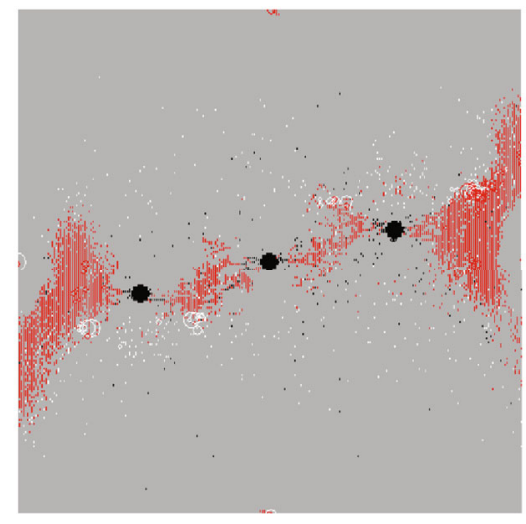

(C) Penetration stage of hydraulic fracture

(b) Signal of acoustic emission
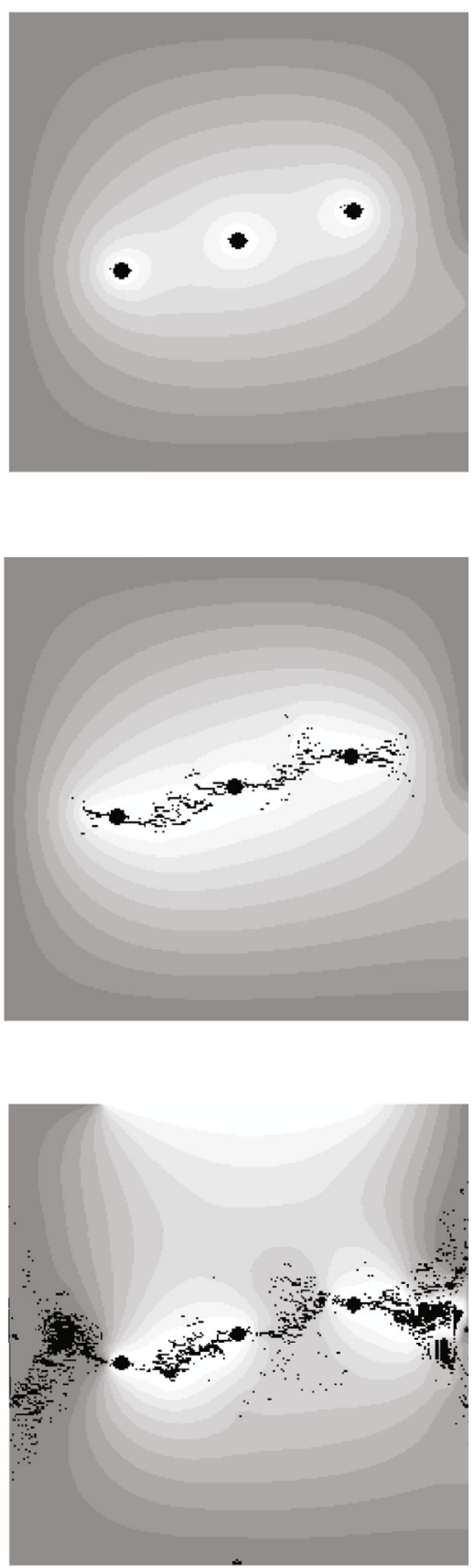

(c) Morphology of hydraulic fracture

Figure 3: The process of fracture initiation and propagation of multihole linear codirectional hydraulic fracturing.

penetrates into the boundary area of the fracture tip. Through continuous water injection, pore water pressure and matrix stress are also superimposed. Therefore, the stress distribution in the boundary region of the fracture tip will also be changed, which helps the tensile fracture to expand along the center line of the adjacent boreholes. When fractures around each borehole intersect with each other, the tensile fractures connect with each other, and a directional failure plane is formed along the direction of the borehole center line.

4.3. Influencing Factors of the Multihole Linear Codirectional Hydraulic Fracture Propagation Law. During the process of multihole linear codirectional hydraulic fracturing, the important factors affecting the rules of hydraulic fracture propagation are as follows: the angle $\theta$ between the line of 

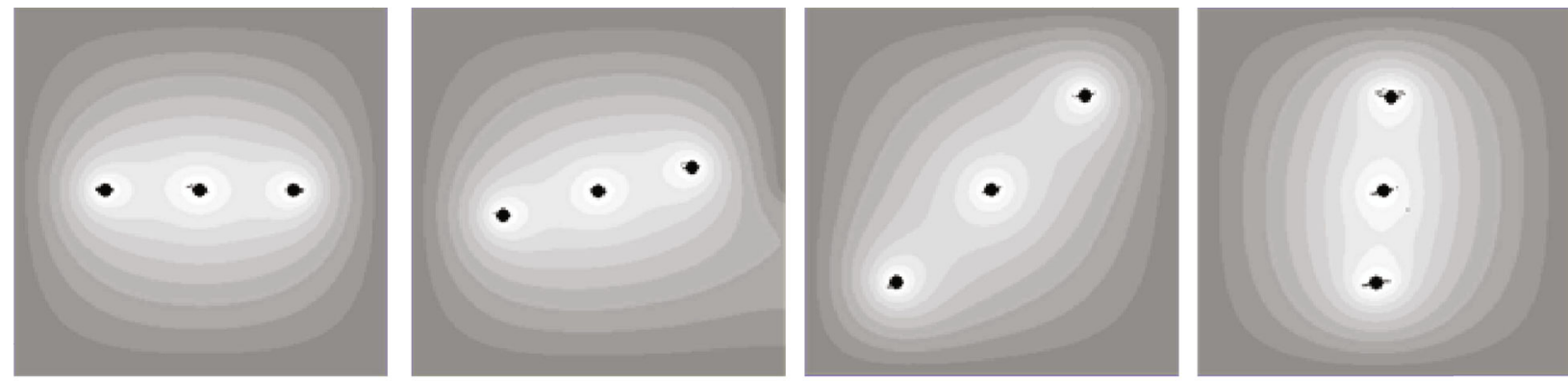

(a) Initiation stage of hydraulic fracture
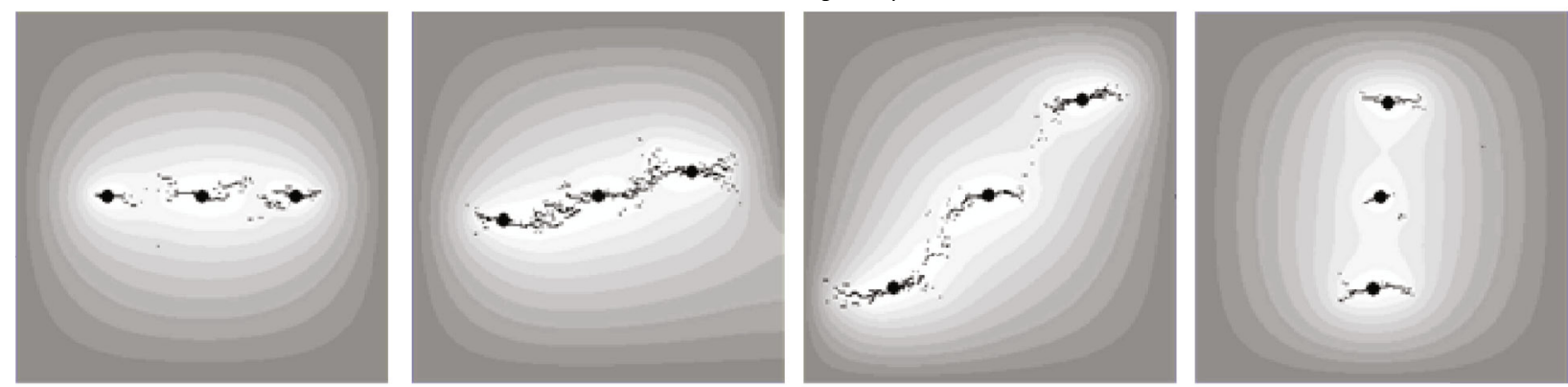

(b) Stable rupture stage of hydraulic fracture
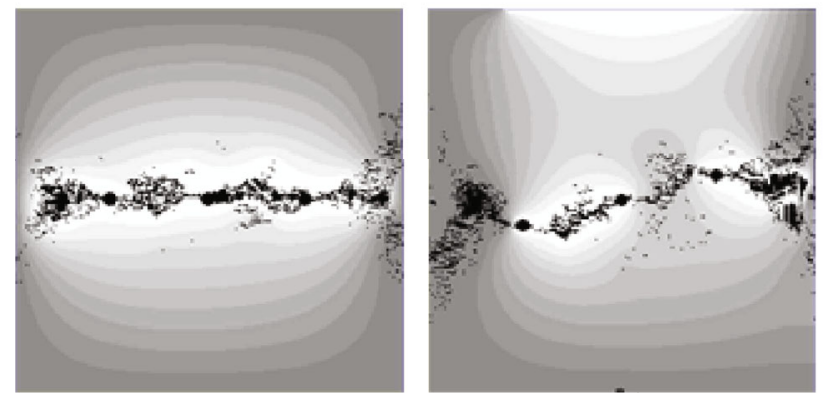

(c) Penetration stage of hydraulic fracture

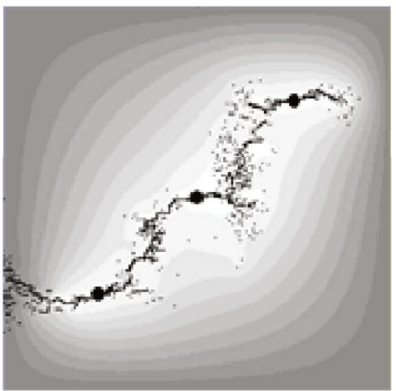

$\theta=15^{\circ}$

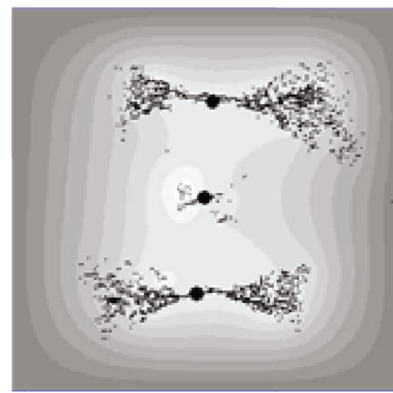

(d) Propagation stage of hydraulic fracture $\theta=75^{\circ}$

FIgURE 4: Initiation, propagation, and penetration process of multihole linear codirectional fractures at different angles between the direction of hole distribution and maximum principle stress $\sigma_{1}$.

the borehole center and the direction of the maximum principal stress $\sigma_{1}$, the difference $\Delta \sigma\left(\Delta \sigma=\sigma_{1}-\sigma_{3}\right)$ between the maximum and the minimum principal stress, and the density of boreholes $N$.

\subsubsection{Angle $\theta$ between the Line of the Borehole Center and the} Direction of Maximum Principal Stress $\sigma_{1}$. In this scheme, $\sigma_{1}=6 \mathrm{MPa}, \sigma_{3}=4 \mathrm{MPa}$, and $D=10 \mathrm{~mm}$. When the value of $\theta$ is $0^{\circ}, 15^{\circ}, 45^{\circ}$, and $75^{\circ}$, the process of initiation, propagation, and connection of hydraulic fractures, respectively, is shown in Figure 4. The results indicate the following: (1) When the values of $\theta$ are $0^{\circ}, 15^{\circ}$, and $45^{\circ}$, the initial initiation fractures are mainly affected by the macroscopic in situ stress field and expand along the direction of the maximum principal stress at first. Meanwhile, under the influence of a coupled effect among boreholes, the hydraulic fracture expands along the direction of the line connected by the center of each fracturing hole and ultimately connects with other holes. (2) When the value of $\theta$ is $15^{\circ}$ and $45^{\circ}$, the initial fracture of each borehole expands along the direction of the maximum principal stress under the action of the macroscopic stress field. When the fracture extends horizontally to a certain length, it deflects under the influence of adjacent holes. The larger the value of $\theta$, the greater the deflection angle of the horizontal fracture. During the process of deflection, all fractures are intersected through micro fractures and finally form linear fractures along the line of the borehole center. (4) When the value of $\theta$ is $75^{\circ}$, the direction of fracture propagation is mainly affected by the direction of the maximum principal stress. Fractures start first along the direction of maximum principle stress. However, the impact of a coupled effect among the boreholes has a minimal effect on the subsequent process of fracture propagation. The external performance of the above two processes is that the deflection angle is very small. Moreover, weak fractures cannot be formed between holes, and effective penetration among fractures is difficult to form. Thus, the purpose of multihole linear codirectional hydraulic fracturing cannot be achieved. In other words, 

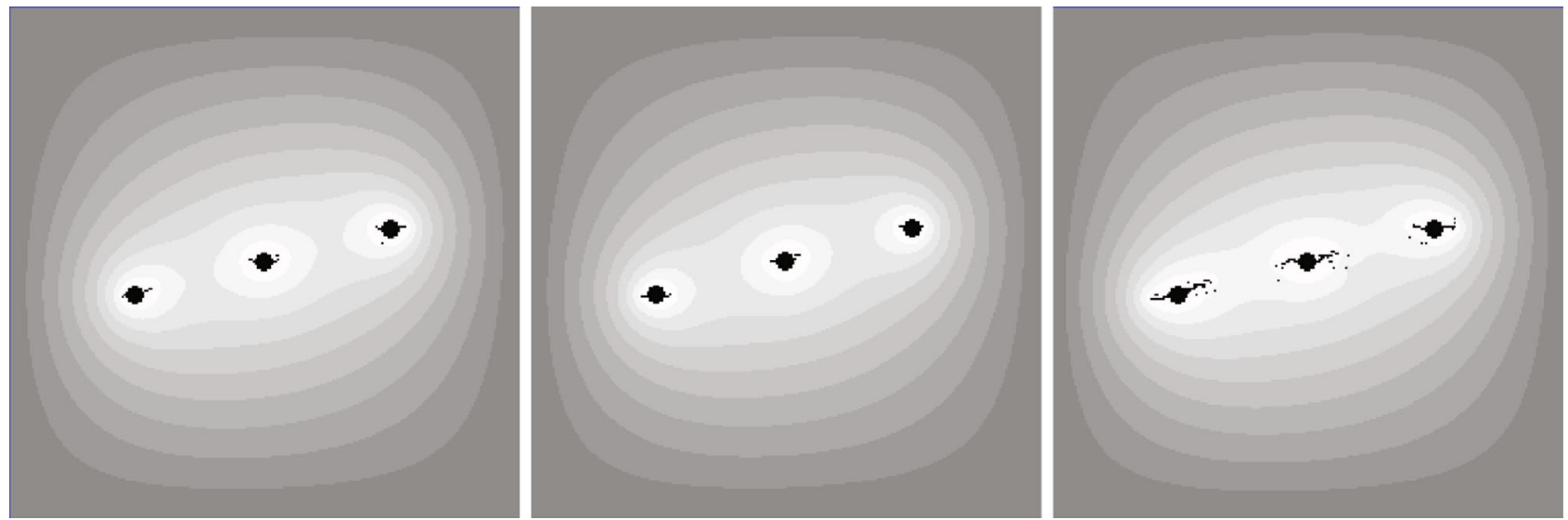

(a) Initiation stage of hydraulic fracture
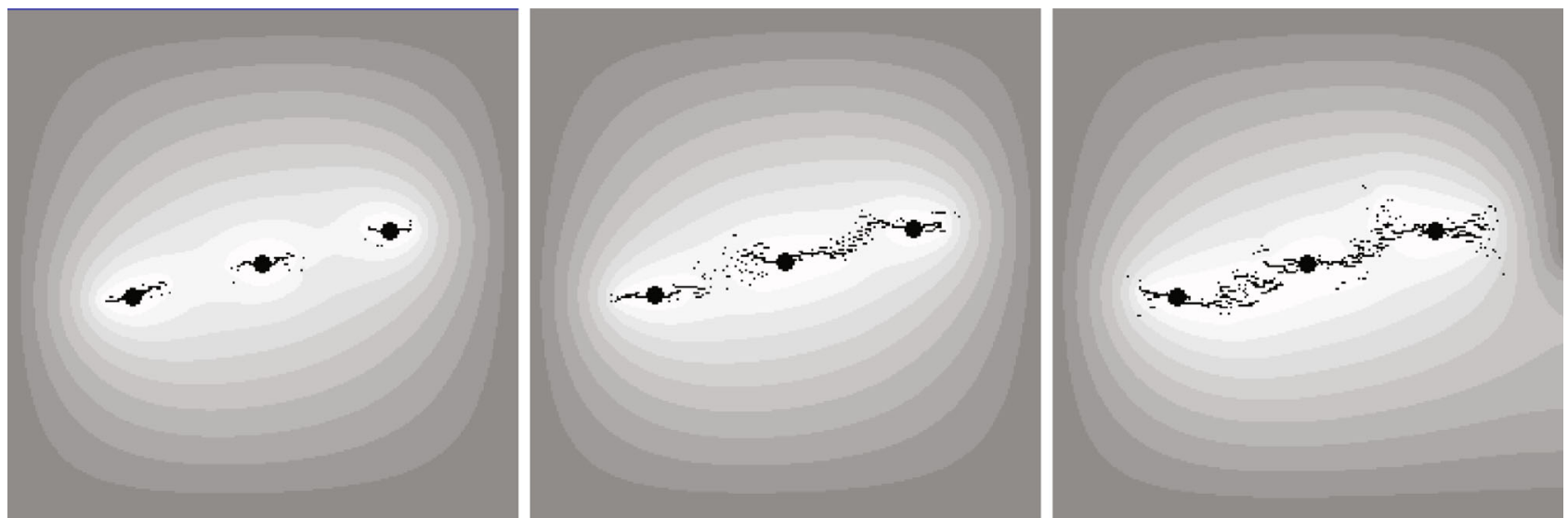

(b) Stable rupture stage of hydraulic fracture
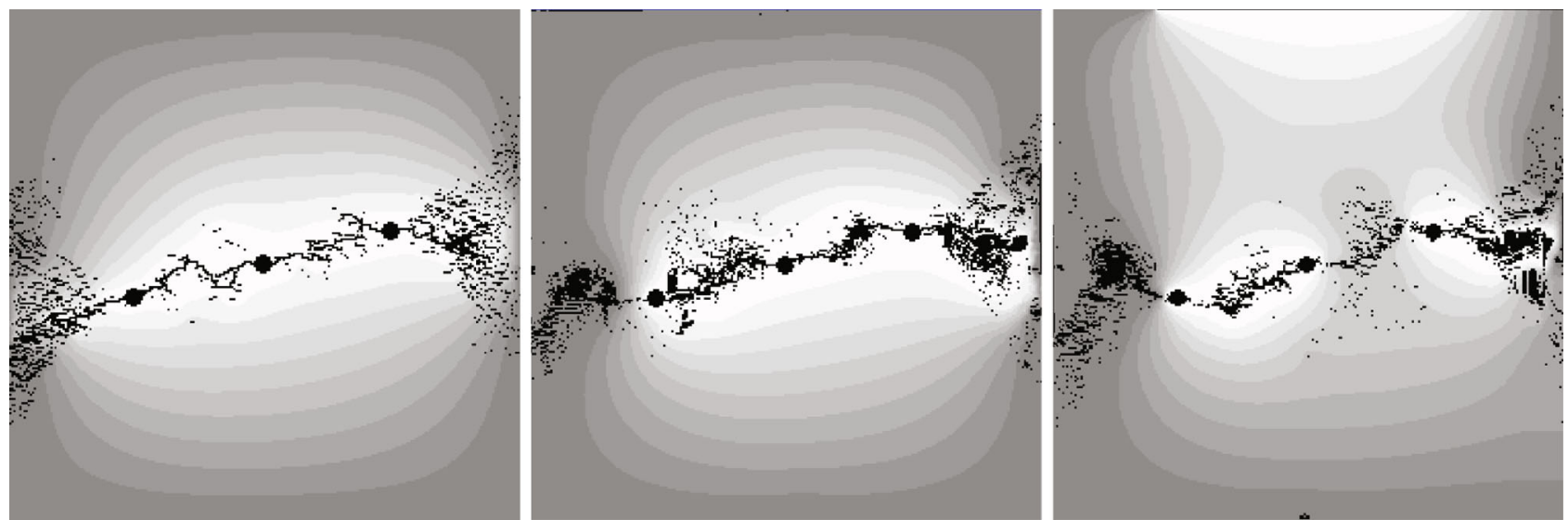

(c) Penetration stage of hydraulic fracture

FIGURE 5: Initiation, propagation, and penetration process of multihole linear codirectional fractures at different principle stress differences: $\Delta \sigma=2 \mathrm{MPa}, \Delta \sigma=3 \mathrm{MPa}$, and $\Delta \sigma=4 \mathrm{MPa}$.

when the value of $\theta$ is greater than a certain value, initiation and propagation of the hydraulic fracture are determined by the in situ stress. These rules are easily observed given the performance of the value of $\theta$ at $75^{\circ}$.

The angle between the direction of the hole distribution and $\sigma_{1}$ has a significant influence on the directional propagation of multihole linear codirectional hydraulic fractures. The smaller the value of $\theta$ is, the easier the goal of multihole linear codirectional hydraulic fracturing is to achieve. Therefore, in the practical application of engineering, the direction of hydraulic fracture propagation can be controlled by adjusting the value of $\theta$ within a certain range to achieve the effect of directional hydraulic fracturing.

4.3.2. The Difference between the Maximum and Minimum Principle Stress $\sigma_{1}$ and $\sigma_{3}$. When $D$ is $10 \mathrm{~mm}, \theta$ is $15^{\circ}$, and $\sigma_{1}$ is $6 \mathrm{MPa}$, the initiation, propagation, and penetration of the multihole linear codirectional hydraulic 
fractures at different principle stress differences of $2 \mathrm{MPa}$, $3 \mathrm{MPa}$, and $4 \mathrm{MPa}$ are shown in Figure 5. It demonstrates the following: (1) the smaller the difference of the main stress, the weaker the effect of macro stress field on the guidance of the hydraulic fracture propagation. Under the condition of small principle stress differences, the hydraulic fracture basically starts to expand from around the hole and then begins to turn when the fracture starts to generate. During the process of hydraulic fracturing, only when the water pressure overcomes the resistance of ground stress can the rock start to rupture. When the stress conditions change, the initial fracture and instable propagation pressure of the rock will also be changed. The smaller the difference of the principal stress is, the lower the initial and instable fracture pressure is. (2) Outside the range among the boreholes, when the difference of the principal stress is small, the effect of the macroscopic stress field on the fracture propagation becomes increasingly weaker. Given that late fracture propagation is easily affected by the extension direction of generated fractures between the holes, the late fracture continues to extend along the direction of the generated fractures. As a result, hydraulic fractures are eventually connected with each other through the direction of the borehole's center, and a good effect of directional hydraulic fracturing is obtained. (3) The smaller the principal stress difference $\Delta$ $\sigma$, the more likely the fractures are to expand linearly along the line direction of the hole's center. The larger the principal stress difference $\Delta \sigma$, the more difficult it is to control the development direction of tensile fractures. The angle between the borehole's center line and the direction of the maximum principal stress becomes increasingly larger.

4.3.3. Density of Boreholes. During the process of multihole linear codirectional hydraulic fracturing, the number of boreholes per unit length is termed as its density. When $D$ is $10 \mathrm{~mm}, \theta$ is $15^{\circ}, \sigma_{1}$ is $6 \mathrm{MPa}$, and $\sigma_{3}$ is $4 \mathrm{MPa}$, the borehole's density $n$ is 3,4 , and 5 , respectively; the initiation, propagation, and penetration process of multihole linear codirectional fracturing is shown in Figure 6. The following findings are revealed: (1) At the beginning of the initial fracture, hydraulic fractures of each borehole will extend first outward along a single curve and then form a divergent expansion path. Fracture initiation of the middle borehole occurs earlier than that of the left and right boreholes. This finding is explained by the fact that under the action of high-pressure water, the tangent stress that is perpendicular to the line direction of the borehole center of the left and right borehole is superimposed at the wall of the middle boreholes. As a result, tangent stress at the wall of the middle borehole is first greater than the tensile strength of the rock, resulting in the tension failure of the rock. Its external performance is demonstrated by the fact that the fracture initiation of the middle borehole occurs earlier than that of the left and right boreholes. The greater the density of the borehole, the smaller the propagation gap between the adjacent boreholes, and the stronger the impact on each other.
When the distance of the hydraulic fracture tip continues to decrease to a certain extent, the coupled effect of the fractures becomes the main factor affecting the rules of hydraulic fracture propagation. The fracture begins to expand and then tends to connect to each other, eventually forming a macroscopic fracture. The greater the number of boreholes, the stronger the coupled effect between the holes, and the more easily the hydraulic fractures will expand along the line of the borehole center. The smaller the space between the borehole, the shorter the time it takes for the hydraulic fracture to penetrate through the borehole center, and the smaller the water pressure at the time of fracture penetration $(4.2 \mathrm{MPa}$ when $n$ is 3, 3.0 MPa when $n$ is 4 , and $2.8 \mathrm{MPa}$ when $n$ is 5 ). The greater the number of boreholes there is, the easier it is to expand along the direction of the connecting line of the borehole center, and the better the effect of directional fracturing.

\section{Mechanism of Multihole Codirectional Hydraulic Fracture Propagation}

5.1. Qualitative Analysis. After the excavation of a single hydraulic borehole or coal bed methane (CBM) well, the surrounding rock stress will be redistributed and a new stress field will be formed. During the process of hydraulic fracturing, a water pressure is generated in the borehole or wellbore, and an additional stress field is generated in the surrounding rock. With this additional stress field superimposed on the surrounding rock stress field formed by excavation, a new stress field is formed. During the process of hydraulic fracturing, the additional stress can be calculated by the thick-walled cylinder formula. At this time, the water pressure in the thick-walled cylinder is $p$, the external pressure is zero, the inner diameter $a$ is the radius of the borehole or wellbore, and the outer diameter is $b(b=\infty)$. It can be obtained that the surrounding rock stress in the rock mass is expressed as follows:

$$
\left\{\begin{array}{l}
\sigma_{r}=\frac{a^{2}\left(b^{2}-r^{2}\right)}{r^{2}\left(b^{2}-a^{2}\right)} p=\frac{a^{2}}{r^{2}} p, \\
\sigma_{\theta}=-\frac{a^{2}\left(b^{2}+r^{2}\right)}{r^{2}\left(b^{2}-a^{2}\right)} p=-\frac{a^{2}}{r^{2}} p .
\end{array}\right.
$$

It can be known from the above equation that $\sigma_{\theta}$ is a tensile stress. When it overcomes the tangential stress caused by excavation and exceeds the tensile strength of surrounding rock, the surrounding rock will undergo tensile failure, and radial cracks will generate.

Figure 7 demonstrates that a large stress concentration is generated at the wall of the borehole. The stress of the fracture tip at the intersection of the borehole's wall and the center line of the two boreholes is more prominent. Based on the fracture mechanics, if the stress intensity factor of the fracture tip is greater than the critical stress intensity factor, the fracture toughness of the material will be exceeded. Then, the fracture begins to expand and spread at a certain speed. 


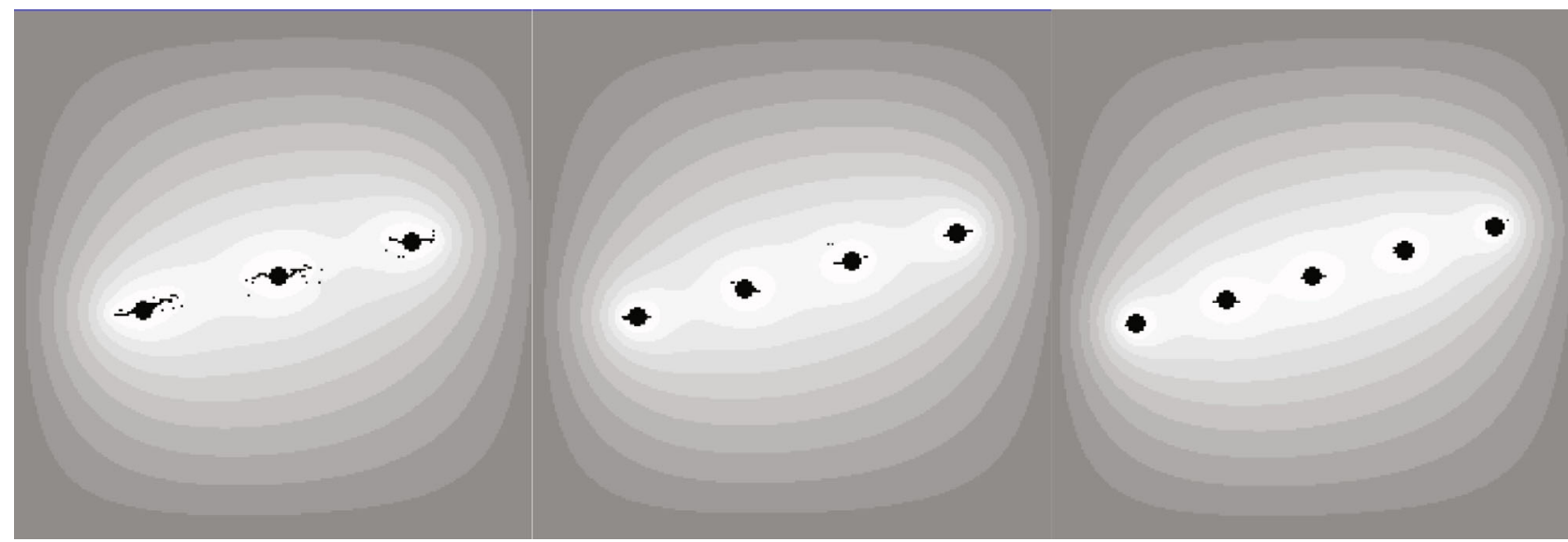

(a) Initiation stage of hydraulic fracture

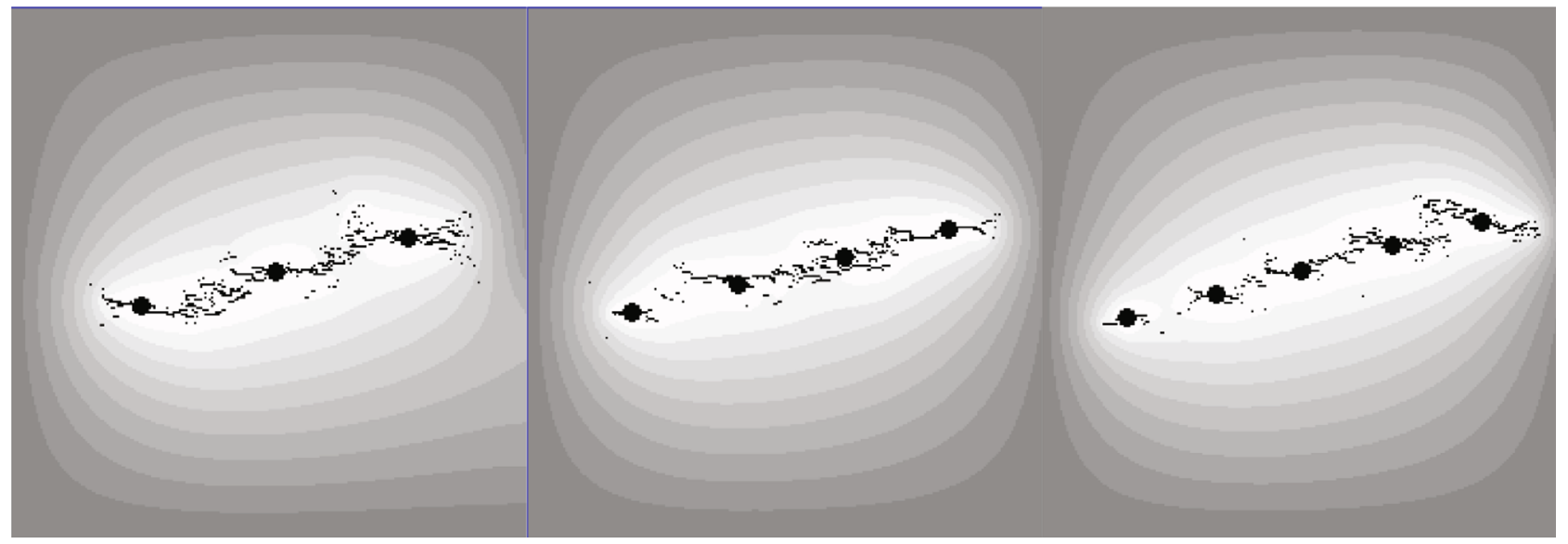

(b) Stable rupture stage of hydraulic fracture

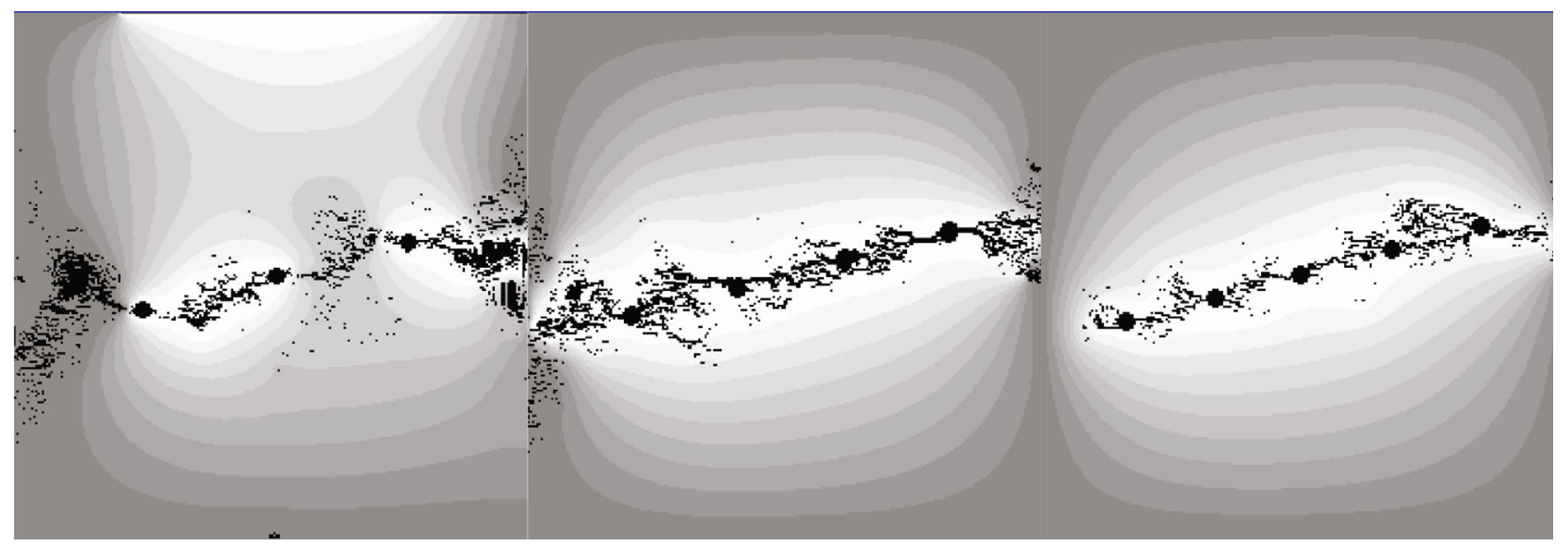

(c) Penetration stage of hydraulic fracture

FIGURE 6: Initiation, propagation, and penetration process of multihole linear codirectional fractures at different densities of borehole: $n=3$, $n=4$, and $n=5$.

Long fractures with preferential propagation are more likely to expand than other short fractures, resulting in cessation of short fracture propagation. The fractures on the inner wall of the two adjacent boreholes expand along the direction of line connected by the borehole center, resulting in the separation of the rock blocks along the direction of the borehole line.
If the layout parameters of the boreholes are selected reasonably, the combined action of all the water pressure inside the boreholes will be applied to the intended fracture surface. When the expansion stress generated by the injected highpressure water is equal to or greater than the tensile strength of the rock surface, the rock will fracture along the intended fracture surface. 

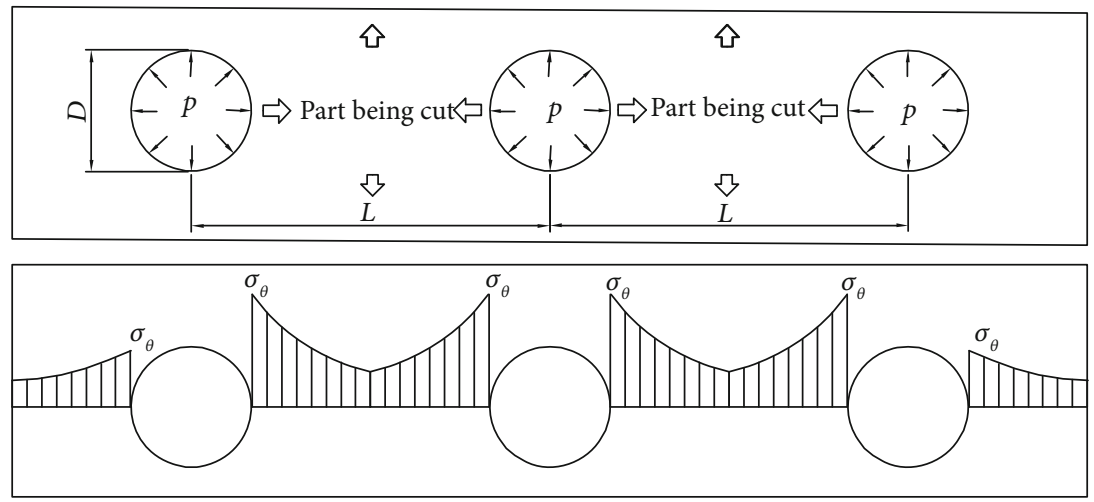

FIGURE 7: Distribution of tangential stress of multihole linear codirectional hydraulic fracturing.

5.2. Quantitative Analysis. For the traditional hydraulic fracturing of single-hole coal and rock mass, the direction of fracture initiation and the final failure surface are parallel to the maximum principal stress due to the existence of the three-dimensional in situ stress field. However, during the process of multihole linear codirectional hydraulic fracturing, the concentration factor of shear stress between the boreholes affected by the superposition of multiple fracture boreholes is greater than that of a single borehole. When hydraulic fracturing is performed in rock mass, the stress distribution of the borehole wall and surrounding rock mass is affected by the boreholes.

In this study, the complex three-dimensional stress problem is simplified as a two-dimensional stress model, and the model is approximately treated as a problem of circular hole stress in an infinite plate with bidirectional forces in elastic mechanics. It is assumed that the stress in the rock mass is uniformly distributed, and the concentration of stress is generated around the borehole wall along the line of the borehole center. When the tangential stress of the borehole inner wall is greater than the tensile strength of the test block, the initial fractures occur in the wall of the borehole. Guided by the theory of hydraulic fracturing controlled by multihole linear control, three boreholes are arranged on the same straight line. The distance between the center of the adjacent two boreholes is $L$, the angle is $\theta$ between the connection line of the borehole center and the horizontal axis, and the radius of the borehole is $r$, which is shown in Figure 8.

Considering the initial stress of the rock, the far edge of the borehole is under the stress of $\sigma_{x}, \sigma_{y}$, and $\tau_{x y}$. When stress loaded inside the borehole is greater than the limit value of the rock, a fracture along the line of the center of the two boreholes will initially appear. This limit value can be defined as the first fracture pressure $P_{b 1}$. Thus, tangential stress generated by the combined action of the fracture pressure $P_{b 1}$ and the in situ rock stress on the wall of the borehole is equal to the tensile strength $T$ of the rock. The following equation can be established [39]:

$$
P_{b 1}=\sigma_{x}+\sigma_{y}-2\left(\sigma_{x}+\sigma_{y}\right) \cos 2 \theta-4 \tau_{x y} \sin 2 \theta+T .
$$

Since the initial fracture has appeared, a repeated fracturing

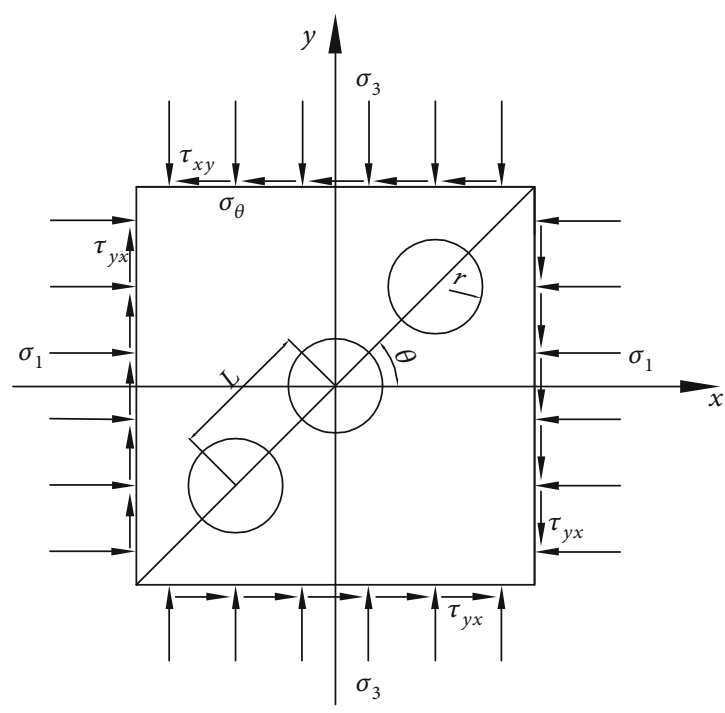

FIGURE 8: Distribution of boreholes.

model controlled by the multihole hydraulic fracturing does not need to overcome the tensile strength $T$ of the rock between the boreholes, i.e., $T=0$. By substituting $T=0$ into equation (11), the secondary fracture pressure $P_{b 2}$ can be obtained:

$$
P_{b 2}=\sigma_{x}+\sigma_{y}-2\left(\sigma_{x}+\sigma_{y}\right) \cos 2 \theta-4 \tau_{x y} \sin 2 \theta .
$$

To determine the three components of the original rock stress, a test of hydraulic fracturing controlled by three directions $\left(\theta_{1}, \theta_{2}, \theta_{3}\right)$ is necessary. Three fracture pressures calculated by the equations can be, respectively, written as $\mathrm{P}_{\mathrm{b} 2}^{\prime}$, $\mathrm{P}_{\text {b2 }}^{\prime \prime}$, and $\mathrm{P}^{\prime \prime \prime}{ }_{\text {b2 }}$. A linear algebraic system, in which $\sigma_{x}, \sigma_{y}$, and $\sigma_{x y}$ of the original in situ stress are regarded as unknown numbers, is established $[40,41]$ :

$$
\left\{\begin{array}{l}
\int 11_{\sigma_{x}} \int 21_{\sigma_{x}}+\int 31_{\sigma_{x}}=P_{b 2}^{\prime}, \\
\int 12_{\sigma_{x}} \int 22_{\sigma_{x}}+\int 32_{\sigma_{x}}=P_{b 2}^{\prime}, \\
\int 13_{\sigma_{x}} \int 23_{\sigma_{x}}+\int 33_{\sigma_{x}}=P_{b 2}^{\prime} .
\end{array}\right.
$$


After the original rock stress of $\sigma_{\mathrm{x}}, \sigma_{\mathrm{y}}$, and $\tau_{\mathrm{xy}}$ is solved, the maximum and minimum principal stress and their direction can be obtained combining equations (12) and (13):

$$
\left\{\begin{array}{l}
\sigma_{1}=\frac{1}{2}\left(\sigma_{x}+\sigma_{y}\right)+\frac{1}{2} \sqrt{\left(\sigma_{x}+\sigma_{y}\right)^{2}+4 \tau_{x y}^{2}} \\
\sigma_{3}=\frac{1}{2}\left(\sigma_{x}+\sigma_{y}\right)-\frac{1}{2} \sqrt{\left(\sigma_{x}+\sigma_{y}\right)^{2}+4 \tau_{x y}^{2}} \\
\alpha=\frac{1}{2} \operatorname{arctg} \frac{2 \tau_{x y}}{\sigma_{x}-\sigma_{y}}
\end{array}\right.
$$

During the process of multihole linear codirectional hydraulic fracturing, when the maximum principle stress and minimum principle stress are nearly equal, the development of tensile fractures of boreholes is not restricted by the state of the in situ stress, and the main stress direction $\alpha$ can be arbitrarily changed. When the ratio of maximum and minimum principle stress is greater than 1.5, it becomes more difficult to control the development of borehole tensile fracture, and its external performance is demonstrated by the fact that the angle between the borehole center line and the direction of the maximum principal stress becomes increasingly larger [40, 41]. This finding is consistent with the results of numerical simulation in Section 4.3.2. In addition, due to the intersection and penetration of fractures around multiple boreholes, the tensile fractures of multihole linear codirectional hydraulic fracturing extend along the central line of the adjacent boreholes.

\section{Conclusions}

In this paper, a numerical simulation method is used to study the basic law of multihole linear codirectional hydraulic cracking. The experimental results demonstrate the following: (1) The process of multihole linear codirectional hydraulic fracturing can be divided into four stages: water injection boost, fracture initiation, stable fracture rupture, and fracture connection. (2) Due to the coupled effect between boreholes, multihole linear codirectional hydraulic fractures just start to crack and then begin to turn, resulting in the final propagation and connection of hydraulic fractures along the direction of the center line of the borehole. (3) When the value of $\theta$ is in a certain range, the initial fracture of each borehole expands along the direction of the maximum principal stress. However, when the fracture extends to a certain length, deflection occurs. The greater the value of $\theta$, the greater the deflection angle of the horizontal fracture. (4) The smaller the difference of the principal stress is, the more likely the fracture is to expand linearly along the direction of hole distribution. On the contrary, it is more difficult to control the development of tensile fracture of the borehole and the angle between the borehole center line and the direction of the maximum principal stress is larger. (5) The more the boreholes, the easier it is to expand along the direction of the center line of the borehole, and the better the effect of directional fracturing. The smaller the spacing of borehole, the less time it takes for the hydraulic fracture to be connected along the center line of the borehole, and the smaller the water pressure at the connection of the fractures.

\section{Data Availability}

The data in the manuscript can be available on request through Weiyong Lu, whose email address is 489698551@qq.com.

\section{Conflicts of Interest}

The authors declare that they have no conflicts of interest.

\section{Acknowledgments}

This study is funded by the Scientific and Technological Innovation Programs of Higher Education Institutions in Shanxi (STIP) (No. 2019L0938), the Special Project of 2019 Plan for the Introduction of High-Level Scientific and Technological Talents in Development Zone of Lvliang City (Development of automatic disassembly platform for hydraulic support pin shaft), the Key Innovation Team for Fault Diagnosis and Health Management Technology of Coal Mine Machinery Equipment of "1331 Project" in Shanxi Province (No. TD201812), the Science and Technology Project of Lvliang City in 2019 (Pressure relief and permeability improvement technology by integrated hydraulic flushing and cutting for low permeability coal seam containing methane), the Research Start-up Funding of Doctors in Luliang University (No. 1901010145), the National Natural Science Foundation of China (No.41872188), and the Natural Science Foundation of Shanxi Province-Mechanical behaviour and breaking mechanism of three-axis fracture of weak and fractured coal body in coalbed methane mining (No. 201901D111330), which is gratefully acknowledged.

\section{References}

[1] C. Lin, J. Deng, Y. Liu, Q. Yang, and H. Duan, "Experiment simulation of hydraulic fracture in colliery hard roof control," Journal of Petroleum Science and Engineering, vol. 138, pp. 265-271, 2016.

[2] B. Yu, R. Gao, T. Kuang, B. Huo, and X. Meng, "Engineering study on fracturing high-level hard rock strata by ground hydraulic action," Tunnelling and Underground Space Technology, vol. 86, pp. 156-164, 2019.

[3] B. Huang, J. Liu, and Q. Zhang, "The reasonable breaking location of overhanging hard roof for directional hydraulic fracturing to control strong strata behaviors of gob-side entry," International Journal of Rock Mechanics and Mining Sciences, vol. 103, pp. 1-11, 2018.

[4] Y. Wang, J. Yang, M. He et al., "Test of a liquid directional roof-cutting technology for pressure-relief entry retaining mining," Journal of Geophysics and Engineering, vol. 16, no. 3, pp. 620-638, 2019.

[5] B. Huang, Q. Cheng, X. Zhao, and C. Kang, "Hydraulic fracturing of hard top coal and roof for controlling gas during the initial mining stages in longwall top coal caving: a case study," Journal of Geophysics and Engineering, vol. 15, no. 6, pp. 2492-2506, 2018. 
[6] B. Huang, Y. Wang, and S. Cao, "Cavability control by hydraulic fracturing for top coal caving in hard thick coal seams," International Journal of Rock Mechanics and Mining Sciences, vol. 74, pp. 45-57, 2015.

[7] L. Dou, C. P. Lu, Z. L. Mu, and M. S. Gao, "Prevention and forecasting of rock burst hazards in coal mines," Mining Science and Technology (China), vol. 19, no. 5, pp. 585591, 2009.

[8] L. You, Y. Kang, Q. Chen, C. Fang, and P. Yang, "Prospect of shale gas recovery enhancement by oxidation-induced rock burst," Natural Gas Industry B, vol. 4, no. 6, pp. 449-456, 2017.

[9] H. He, L. Dou, J. Fan, T. du, and X. Sun, "Deep-hole directional fracturing of thick hard roof for rockburst prevention," Tunnelling and Underground Space Technology, vol. 32, pp. 34-43, 2012.

[10] B. Huang and W. Lu, "A fluid-solid coupling mathematical model of methane driven by water in porous coal," Geofluids, vol. 2018, Article ID 7049830, 17 pages, 2018.

[11] W. Lu, B. Huang, and X. Zhao, "A review of recent research and development of the effect of hydraulic fracturing on gas adsorption and desorption in coal seams," Adsorption Science \& Technology, vol. 37, no. 5-6, pp. 509-529, 2019.

[12] D. Li, Y. Lu, Y. Rong et al., "Rapid uncovering seam technologies for large cross-section gas tunnel excavated through coal seams using directional hydraulic fracturing," Rock and Solid Mechanics, vol. 40, no. 1, pp. 363-369, 2019.

[13] J. Q. Deng, C. Lin, Q. Yang, Y. R. Liu, Z. F. Tao, and H. F. Duan, "Investigation of directional hydraulic fracturing based on true tri-axial experiment and finite element modeling," Computers and Geotechnics, vol. 75, pp. 28-47, 2016.

[14] J. Deng, Q. Yang, Y. Liu, Y. Liu, and G. Zhang, “3D finite element modeling of directional hydraulic fracturing based on deformation reinforcement theory," Computers and Geotechnics, vol. 94, pp. 118-133, 2018.

[15] Q. He, F. T. Suorineni, T. Ma, and J. Oh, "Parametric study and dimensional analysis on prescribed hydraulic fractures in cave mining," Tunnelling and Underground Space Technology, vol. 78, pp. 47-63, 2018.

[16] B. Zhang, J. Liu, S. G. Wang et al., "Impact of the distance between pre-existing fracture and wellbore on hydraulic fracture propagation," Journal of Natural Gas Science and Engineering, vol. 57, pp. 155-165, 2018.

[17] Y. Liu, B. Xia, and X. Liu, "A novel method of orienting hydraulic fractures in coal mines and its mechanism of intensified conduction," Journal of Natural Gas Science and Engineering, vol. 27, pp. 190-199, 2015.

[18] Q. Zou and B. Lin, "Fluid-solid coupling characteristics of gasbearing coal subjected to hydraulic slotting: an experimental investigation," Energy \& Fuels, vol. 32, no. 2, pp. 1047-1060, 2018.

[19] B. Lin and C. Shen, "Coal permeability-improving mechanism of multilevel slotting by water jet and application in coal mine gas extraction," Environmental Earth Sciences, vol. 73, no. 10, pp. 5975-5986, 2015.

[20] B. Huang, X. Zhao, S. Chen, and J. Liu, "Theory and technology of controlling hard roof with hydraulic fracturing in underground mining," Chinese Journal of Rock Mechanics and Engineering, vol. 36, no. 12, pp. 2954-2970, 2017.
[21] B. Lin, F. Yan, C. Zhu et al., "Cross-borehole hydraulic slotting technique for preventing and controlling coal and gas outbursts during coal roadway excavation," Journal of Natural Gas Science and Engineering, vol. 26, pp. 518-525, 2015.

[22] B. Huang, S. Chen, and X. Zhao, "Hydraulic fracturing stress transfer methods to control the strong strata behaviours in gob-side gateroads of longwall mines," Arabian Journal of Geosciences, vol. 10, no. 11, 2017.

[23] Y. Cheng, Y. Lu, Z. Ge, L. Cheng, J. Zheng, and W. Zhang, "Experimental study on crack propagation control and mechanism analysis of directional hydraulic fracturing," Fuel, vol. 218, pp. 316-324, 2018.

[24] C. Zhai, M. Li, C. Sun, J. Zhang, W. Yang, and Q. Li, "Guidingcontrolling technology of coal seam hydraulic fracturing fractures extension," International Journal of Mining Science and Technology, vol. 22, no. 6, pp. 831-836, 2012.

[25] X. Zhao, B. Huang, and Z. Wang, "Experimental investigation on the basic law of directional hydraulic fracturing controlled by dense linear multi-hole drilling," Rock Mechanics and Rock Engineering, vol. 51, no. 6, pp. 1739-1754, 2018.

[26] M. S. Bruno and F. M. Nakagawa, "Pore pressure influence on tensile fracture propagation in sedimentary rock," International Journal of Rock Mechanics and Mining Sciences, vol. 28, no. 4, pp. 261-273, 1991.

[27] Q. Gao, Y. Cheng, S. Han, C. Yan, and L. Jiang, "Numerical modeling of hydraulic fracture propagation behaviors influenced by pre-existing injection and production wells," Journal of Petroleum Science and Engineering, vol. 172, pp. 976-987, 2019.

[28] X. Fu, H. L. Liu, T. H. Yang, and H. W. Yang, "Simulating directional hydraulic fracturing through coal seam drilling hole," Journal of Northeastern University (Natural Science), vol. 32, no. 10, pp. 1480-1483, 2011.

[29] X. Liu, Z. Qu, T. Guo et al., "An innovative technology of directional propagation of hydraulic fracture guided by radial holes in fossil hydrogen energy development," International Journal of Hydrogen Energy, vol. 44, no. 11, pp. 5286-5302, 2019.

[30] T. Guo, Z. Rui, Z. Qu, and N. Qi, "Experimental study of directional propagation of hydraulic fracture guided by multi-radial slim holes," Journal of Petroleum Science and Engineering, vol. 166, pp. 592-601, 2018.

[31] L. Li, S. Liu, and D. Li, "A case based reasoning algorithm for enterprises' integration of informatization and industrialization," International Journal of Database Theory and Application, vol. 9, no. 7, pp. 169-178, 2016.

[32] L. C. Li, C. A. Tang, G. Li, S. Y. Wang, Z. Z. Liang, and Y. B. Zhang, "Numerical simulation of 3D hydraulic fracturing based on an improved flow-stress-damage model and a parallel fem technique," Rock Mechanics \& Rock Engineering, vol. 45, no. 5, pp. 801-818, 2012.

[33] W. Weibull, "A statistical distribution of wide applicability," Journal of Applied Mechanics, vol. 18, pp. 293-297, 1951.

[34] M. A. Biot, "General theory of three-dimensional consolidation," Journal of Applied Physics, vol. 12, no. 2, pp. 155-164, 1941.

[35] T. Yang, C. A. Tan, W. Zhu, and Q. Y. Feng, "Coupling analysis of seepage and stresses in rock failure process," Chinese Jounal of Geotechnical Engineering, vol. 23, no. 4, pp. 489-493, 2001.

[36] W. Zhu and T. F. Wong, "Network modeling of the evolution of permeability and dilatancy in compact rock," Journal of 
Geophysical Research Solid Earth, vol. 104, no. B2, pp. 29632971, 1999.

[37] J. Lemaitre and R. Desmorat, "Failure of brittle and quasibrittle materials," in Engineering Damage Mechanics: Ductile, Creep, Fatigue and Brittle Failures, pp. 321-371, Springer-Verlag Berlin Heidelberg, 2005.

[38] V. I. Klishin, G. Y. Opruk, and A. S. Teleguz, "Ensuring stability of maintained goaf by means of directional hydraulic fracturing (DHF)," Earth and Environmental Science, vol. 84, no. 84, pp. 1-7, 2017.

[39] P. Hao, 3D geostress measurement by sleeve fracturing technique and engineering application, China University of Mining and Technology (Beijing), Beijing, 2014.

[40] W. Chou, W. Li, S. Wei, and N. Xiuquan, "Rockmass stress measurement by sleeve fracturing technique and calculation on initial rockmass stresses," Chinese Jounal of Rock Mechanics and Engineering, vol. 15, no. 1, pp. 40-47, 1996.

[41] W. Chou and S. Wei, "Surrounding rock stress measurement by sleeve fracture," Chinese Journal of Rock Mechanics and Engineering, vol. 11, no. 2, pp. 200-208, 1992. 